\title{
Prevalence and factors associated with depression among hospital admitted patients in South Ethiopia: cross sectional study
}

\author{
Bereket Duko* (D), Marta Erdado and Jemal Ebrahim
}

\begin{abstract}
Objective: Identifying factors associated with depression will help health care providers to design programs which improve quality of services provided to the inpatients. The aim of this study was to assess the prevalence and factors associated with depression among admitted patients at Adare General Hospital, Hawassa, Ethiopia, 2017/2018.

Result: The mean age of the respondents was 38 years (SD \pm 15.39 ). The prevalence of depression was $38 \%$. After adjusting for possible confounding variables; age category of $18-24$ years $[A O R=1.24,95 \mathrm{Cl}(1.08-5.73)$, having cardiovascular disease $[\mathrm{AOR}=2.20), 95 \mathrm{Cl}(1.38-7.28)]$ and being in surgical ward [AOR $=1.92), 95 \mathrm{Cl}(2.13-4.12)]$ had statistically significant association with depression.
\end{abstract}

Keywords: Prevalence, Depression, Associated factor, Inpatient, Ethiopia

\section{Introduction}

Depression is an emotional state which is experienced by most people sometime in life and can manifest as the blues or sadness, grief, mourning, no pathologic or neurotic or in the form of hyperactivity and manic behavior $[1,2]$. The estimated of prevalence of depressive disorder is ranges $5-10 \%$ in care giving settings and it ranks the fourth leading causes of disability in world $[3,4]$.

Studies revealed that family history of depression, substance abuse, suicide, impulsive behavior, severe or chronic medical conditions, being female sex, intimate partner violence and sexual abuse are associated factors of depression $[5,6]$.

According to world health organization estimate, averagely $15 \%$ of global populations experience depression once or more in their stay of life [7, 8]. Depression could result significant morbidity and mortality to hospital admitted patients which is expected to be the second leading causes of disability-adjusted life years [9].

Depressive disorders are more common in hospital admitted patients. One study in Kenya revealed that $42 \%$

\footnotetext{
*Correspondence: berkole.dad@gmail.com
}

Faculty of Health Sciences, College of Medicine and Health Sciences,

Hawassa University, Hawassa, Ethiopia of inpatients experienced mild to severe depression [10]. In addition to this, other studies which are conducted in different setting on the prevalence of depression among admitted patients also showed that $48.5 \%$ in Pakistan [11], 29.4\% in Addis Ababa, Ethiopia [12] and 54.6\% in Mekele, Ethiopia [13]. Being female sex, age $>60$ years, being divorced, being in age 35-44, being in surgical ward and medical ward are factors have statically significant association with depression [10-13]. Therefore, this study aimed to assess the prevalence and associated factors of depression in hospital admitted patient.

\section{Main text}

Study setting and population

Hospital based cross sectional study design was employed from May 2017 to June 2017 at Adare General Hospital, Hawassa, Ethiopia. Adare general hospital is one governmental hospitals in Hawassa, which is located $273 \mathrm{~km}$ away from Addis Ababa, the capital city of Ethiopia. A total 203 admitted patients who are $\geq 18$ years were included for the study from those who unable to communicate because of the severity of illness and with diagnosis of major depressive disorders and other mental illness, and those who were in the operation room during the study period were excluded from the study. We 
had used stratified sampling technique to identify the specific ward of patient admission. Systematic sampling technique was used to recruit patients from each strata.

\section{Data collection}

We have used semi-structured questionnaire to collect socio-demographic, substance use, clinical factors and use Beck depression inventory scale to assess depression. Data was collected through face to face interview. Beck depression inventory scale was used as a screening tool for depression in many epidemiological studies across the world. It consists of 21 questions with a likert scale of $0-3$ providing a total score of 63 . According to the revised version of Beck-II in 1996, the score from 0-13 is considered as normal, $14-19$ as mild, $20-28$ as moderate and 29-63 as severe depression. Those patients who scored moderate and severe considered to have depression [14].

\section{Data processing and analyses}

The collected data was edited, coded, entered into EPI info version 7.1 and was analyzed using SPSS version 20 . We had conducted binary logistic regression to identify risk factors of depression.

\section{Results}

Socio-demographic characteristics of the study participants

Among 203 study participants, 194 patients were involved in the study with mean age of 38 years $(\mathrm{SD} \pm 15.39)$ and resulted a response rate of $95.6 \%$. Out of 194 respondents, $105(54.1 \%)$ were male and $96(49.5 \%)$ were single (Table 1).

\section{Clinical and substance use related characteristics of the study participants}

From the total study participants, $31(16 \%)$ were currently smoking cigarettes, 48 (24.7\%) were drinking alcohol and 44 (22.7\%) were chewing khat (chat) (Table 2).

\section{Prevalence and factors associated depressive symptom among the study participants}

Using Beck depression inventory scale with cut-off point $\geq 21$ revealed that the prevalence of depression was $38 \%$. Being in age category of 18-24, having cardiovascular disease and being admitted in surgical ward were associated with depressive symptom according to binary logistic regression analysis (Table 3 ).

\section{Discussion}

The findings of this study revealed that the overall prevalence of depression among hospital admitted patients was $38 \%$. The study finding was lower than study conducted among hospital admitted patients in Ethiopia [13], in Spain [15], and in Western Asia [16]. On the other hand,
Table 1 Distribution of respondents by their sociodemographic characteristic, Adare General Hospital, Hawassa, Ethiopia, 2017

\begin{tabular}{|c|c|c|}
\hline Category & $\begin{array}{l}\text { Frequency } \\
(n=194)\end{array}$ & Percent (\%) \\
\hline \multicolumn{3}{|l|}{ Age } \\
\hline $18-24$ & 38 & 19.6 \\
\hline $25-34$ & 59 & 30.4 \\
\hline $35-44$ & 40 & 20.6 \\
\hline $45-54$ & 24 & 12.4 \\
\hline$\geq 55$ & 33 & 17.0 \\
\hline \multicolumn{3}{|l|}{ Sex } \\
\hline Male & 105 & 54.1 \\
\hline Female & 89 & 45.9 \\
\hline \multicolumn{3}{|l|}{ Marital status } \\
\hline Single & 65 & 33.5 \\
\hline Married & 96 & 49.5 \\
\hline Divorced & 14 & 7.2 \\
\hline Widowed & 19 & 9.8 \\
\hline \multicolumn{3}{|l|}{ Ethnicity } \\
\hline Sidama & 65 & 33.5 \\
\hline Wolaita & 53 & 27.3 \\
\hline Oromo & 31 & 16.0 \\
\hline Amhara & 24 & 12.4 \\
\hline Others & 20 & 10.3 \\
\hline \multicolumn{3}{|l|}{ Religion } \\
\hline Orthodox & 67 & 34.5 \\
\hline Muslim & 89 & 45.9 \\
\hline Protestant & 25 & 12.9 \\
\hline Catholic & 13 & 6.7 \\
\hline \multicolumn{3}{|l|}{ Education } \\
\hline Unable to read and write & 24 & 12.4 \\
\hline No formal education & 15 & 7.7 \\
\hline Primary & 48 & 24.7 \\
\hline Secondary & 36 & 18.6 \\
\hline College and above & 70 & 36.1 \\
\hline \multicolumn{3}{|l|}{ Occupation } \\
\hline Governmental employee & 34 & 17.5 \\
\hline House wife & 21 & 10.8 \\
\hline Farmer & 27 & 13.9 \\
\hline Non-governmental & 42 & 21.6 \\
\hline Merchant & 36 & 18.6 \\
\hline Student & 28 & 14.4 \\
\hline Others & 40 & 20.6 \\
\hline
\end{tabular}

the current finding is higher than the study conducted in Paris metropolitan area [17] and in Sweden [18]. The Difference might be difference in sample size, data collection tool and socio-cultural difference.

Being in age category of $18-24$ had significant association with depressive symptom. This finding is congruent 
Table 2 Clinical and substance related factors among admitted patients, Adare General Hospital, Hawassa, Ethiopia, 2017

\begin{tabular}{lcc}
\hline Variables & Frequency & Percent \\
\hline IIness & & \\
Cardiovascular disorder & & \\
Yes & 38 & 19.6 \\
No & 156 & 80.4 \\
Neurologic disorder & & \\
$\quad$ Yes & 5 & 2.6 \\
$\quad$ No & 189 & 97.4 \\
Gastro-intestinal disorder & & \\
Yes & 52 & 26.8 \\
No & 142 & 73.2 \\
Substance use & & \\
Consuming tobacco products & & \\
Yes & 31 & 15.9 \\
$\quad$ No & 163 & 84.1 \\
Drinking alcohol & & \\
Yes & 48 & 24.7 \\
$\quad$ No & 146 & 75.3 \\
Chewing chat & & \\
Yes & 44 & 22.7 \\
$\quad$ No & 150 & 77.3 \\
Ward & & \\
Surgical & & \\
Gynaecology & 58 & 29.9 \\
Medical & 54 & 42.3 \\
\hline
\end{tabular}

Table 3 Factors associated with depressive symptom among admitted patients at Adare General Hospital, Hawassa, Ethiopia, 2017

\begin{tabular}{llll}
\hline Variables & Depression & COR $(\mathrm{Cl})$ & AOR $(\mathrm{Cl})$ \\
& Yes No & &
\end{tabular}

\begin{tabular}{lllll}
\hline Age category & & & & \\
$18-24$ & 28 & 10 & $1.60(1.07-9.56)$ & $1.24(1.08-5.73)$ \\
$25-34$ & 18 & 41 & $0.25(0.10-4.62)$ & $0.34(0.12-2.43)$ \\
$35-44$ & 14 & 26 & $0.30(0.19-6.80)$ & $0.38(0.13-1.09)$ \\
$45-54$ & 11 & 13 & $0.48(0.16-1.14)$ & $0.44(0.14-1.41)$ \\
$\geq 55$ & 21 & 12 & 1 & 1 \\
Cardiovascular disease & & & \\
Yes & 24 & 14 & $0.275(0.13-0.57)$ & $2.20(1.38-7.28)$ \\
No & 50 & 106 & 1 & 1 \\
Gastrointestinal disease & & & \\
Yes & 26 & 26 & $0.51(0.26-0.97)$ & $0.44(0.27-5.47)$ \\
No & 94 & 48 & 1 & 1 \\
Ward & & & & $1.92(2.13-4.12)$ \\
Surgical & 38 & 20 & $3.87(1.26-5.35)$ & $1.01(0.85-2.87)$ \\
Gynaecology & 18 & 36 & $1.01(0.85-2.87)$ & 1 \\
Medical & 27 & 55 & 1 &
\end{tabular}

with other studies [13]. People aged 18-24 years have the highest prevalence of mental disorders of any age group. This is supported by many more literatures worldwide. There was no statistically significant association between depression and gender in this study.

Patients who had cardiovascular disorder were 2.2 times more likely to have depressive symptom when compared to the patients who had no cardiac problems. This is due to the fact that depression is more common in cardiac patients, this would seem that either depression leads to cardiovascular disorder or cardiovascular disorder leads to depression or may be both $[19,20]$.

Patients who were admitted in surgical ward for surgical management were 3.87 times more likely to have depression when compared to patient admitted to medical ward. This might be due to the fact that having surgical management by itself creates stress, admission in hospital is stressful and some other different factors like a kind of disease, hospital environment, patient's concern about being away from their family and missing their job.

\section{Conclusion}

According to the current study finding, depression was high in admitted patients in the study setting. Being age category 18-24, having cardiovascular disorder and being in surgical ward had statistically significant association with depression. They recommends to have further research on probable risk factors of depression to strengthen the current result.

\section{Limitation of the study}

We didn't do detailed validation study for Beck's depression inventory scale. This might under or overestimate the study findings. The study didn't include detailed clinical factors which might contribute for depressive symptom.

\section{Authors' contributions}

$\mathrm{ME}$ and $\mathrm{BD}$ conceived the study and were involved in the study design, reviewed the article, analysis, report writing and drafted the manuscript. BD and $\mathrm{J}$ were involved in the study design and analysis. All authors read and approved the final manuscript.

\section{Acknowledgements}

We acknowledge the study institution for their help, the study participants, data collectors andsupervisor for their cooperation in providing all necessary information.

\section{Competing interests}

The authors declare that they have no competing interests.

Availability of data and materials

All relevant data are within the paper.

\section{Consent for publication}

Not applicable. 


\section{Ethical approval and consent to participate}

Ethical clearance for this study was obtained from the Institutional Research and Ethics ReviewCommittee of College of Medicine and Health Sciences, Hawassa University, Ethiopia.Permission letter was obtained and submitted to Adare General Hospital, Hawassa, Ethiopia. Studyparticipants were informed about their rights to interrupt the interview at any time and writteninformed consent was obtained from each study participants. Confidentiality was maintained at alllevels of the study. Patients who were found to have moderate to severe depressive symptoms werereferred to psychiatry clinics for further investigations.

\section{Funding}

No funding source.

\section{Publisher's Note}

Springer Nature remains neutral with regard to jurisdictional claims in published maps and institutional affiliations.

Received: 19 December 2018 Accepted: 31 January 2019

Published online: 04 February 2019

\section{References}

1. National Institute for Health and Clinical Excellence. Depression: the treatment and management of depression in adults (updated edition). London: NICE; 2009. p. 6-11.

2. National Institute of Mental Health. Depression. Bethesda: National Institute of Mental Health; 2013. p. 81-86.

3. Katonwlin EH, Kroenke K. The association of depression, anxiety with media symptoms burden in patient with chronic medical illness. Gen Hosp Psychiatry. 2007;29:147-55.

4. Wells KB, Stewart A, Hays RD, Burnam MA, Rogers W. The functioning and wellbeing of depressed patient result from outcome study. JAMA. 1989:292:914-9.

5. University of Maryland Medical Center. Depression—risk factors. Baltimore: University of Maryland Medical Center; 2013. p. 140-157.

6. WHO, 2015, Depression, https://www.who.int/mediacentre/factsheets/ fs369/en/

7. Kastrup MC, Ramos AB. Global mental health—secondary publication. Dan Med Bull. 2007;54(1):42-3.

8. Andrade L, Caraveo-Anduaga JJ, Berglund P, et al. The epidemiology of major depressive episodes: results from the International Consortium of Psychiatric Epidemiology (ICPE) Surveys. Int J Methods Psychiatr Res. 2003;12(1):3-21.

9. World Health Organization. Mental health and a state of well-being Geneva: World Health Organization; 2012. p. 41-59.

10. Ndetei DM, Khasakhala LI, Kuria MW, Mutiso VN, Ongecha-Owuor FA, Kokonya DA. The prevalence of mental disorders in adults in different level general medical facilities in Kenya. Ann Gen Psychiatry. 2009;8(1):1-8

11. Rahman AS, Aziz A, Jamal Q, Siddiqui MA, Razia M, Ali R. Prevalence of recognized and unrecognized depression among medical and surgical patients in a tertiary care hospital. J Pakistan Med Assoc. 2015;65:1320.

12. Assefa B, Duko B, Ayano G, Mihretie G. Prevalence and factors associated with depressive symptoms among patient with chronic kidney disease (CKD) in Black Lion Specialized Hospital and Saint Paulo's Hospital Millennium Medical College, Addis Ababa Ethiopia. J Psychiatry. 2016;19:6.

13. Hailu A, Mandush A, Berhe KK, Gebru HB, Aregay A. Prevalence and its determinants among adult patients admitted in governmental hospitals mekele, tigray, Ethiopia, cross sectional study. Int J Pharmaceut Sci Res. 2013;4(5);1882-92

14. Beck AT, Steer RA, Ball R, Ranieri W. Comparison of beck depression inventories_- I and II in psychiatry outpatients. J Person Assess. 1996;67:588-97.

15. Guallar-Castillón P, Magariños-Losada MdM, Montoto-Otero C, Tabuenca Al, Rodríguez-Pascual C, Olcoz-Chiva M, et al. Prevalence of depression and associated medical and psychosocial factors in elderly hospitalized patients with heart failure in Spain. Revista Española de Cardiología (English Edition). 2006;59(08):770-8.

16. Hadi N, Jamali E, Rahimi F. The prevalence of anxiety and depression in adult hospitalized patients in internal and surgical wards of Shiraz Hospitals-1387. Shiraz E Med J. 2010;11(3):137-47.

17. American Psychiatric Association (APA). Diagnostic and statistical manual of mental disorders, 4th Ed. Washington DC: APA; 2003.

18. Menckel E, Viiasara E. Threat and violence in Swedish care and validation of anticipated turnover model for urban registered nurses. Nurs Res. 1993;16(1):376-85.

19. Hare DL, Thompson PL. Depression and coronary heart disease, coronary care manuel. Eur Heart J. 2011;35:641-5.

20. Nicholson A, Kuper H, Hemingway H. Depression as an etiologic and prognostic factor in coronary heart disease: a meta-analysis of 6362 events among 146538 participants in 54 observational studies. Eur Heart J. 2006:27:2763-74.
Ready to submit your research? Choose BMC and benefit from:

- fast, convenient online submission

- thorough peer review by experienced researchers in your field

- rapid publication on acceptance

- support for research data, including large and complex data types

- gold Open Access which fosters wider collaboration and increased citations

- maximum visibility for your research: over $100 \mathrm{M}$ website views per year

At $\mathrm{BMC}$, research is always in progress.

Learn more biomedcentral.com/submissions 